\title{
MiR-221-3p-Mediated Downregulation of MDM2 Reverses the Paclitaxel Resistance of Non-Small Cell Lung Cancer in Vitro and in Vivo
}

\section{Liwei Ni}

Second Affiliated Hospital of Soochow University https://orcid.org/0000-0003-3870-417X Jianhao Xu

First Peoples Hospital of Kunshan

\section{Fenglun Zhao}

Second Affiliated Hospital of Soochow University

Xiaoxiao Dai

Second Affiliated Hospital of Soochow University

Jialong Tao

Second Affiliated Hospital of Soochow University

Jie Pan

Second Affiliated Hospital of Soochow University

\section{Aiming Shi}

Second Affiliated Hospital of Soochow University

\section{Zhu Shen}

Second Affiliated Hospital of Soochow University

Cunjin Su ( $\nabla$ sucjgh@vip.163.com)

Second Affiliated Hospital of Soochow University

Yusong Zhang ( $\sim$ zhangyusong19@163.com )

Second Affiliated Hospital of Soochow University

\section{Primary research}

Keywords: miR-221-3p, MDM2, P53, paclitaxel resistance, non-small cell lung cancer

Posted Date: June 22nd, 2020

DOI: https://doi.org/10.21203/rs.3.rs-36548/v1

License: (1) (1) This work is licensed under a Creative Commons Attribution 4.0 International License. Read Full License 
Version of Record: A version of this preprint was published at European Journal of Pharmacology on May 1st, 2021. See the published version at https://doi.org/10.1016/j.ejphar.2021.174054. 


\section{Abstract}

Background: MicroRNAs (miRNAs) are involved in the initiation and development of cancer, and participate in drug resistance. Paclitaxel (PTX) is first-line chemotherapy drug for advanced non-small cell lung cancer (NSCLC). The abnormal miRNA expression in NSCLC and its association with chemotherapy drug resistance remains largely unknown. The study aimed to investigate the aberrant expression of miR221-3p in NSCLC and to elucidate its molecular mechanisms in relation to PTX resistance.

Methods: Quantitative polymerase chain reaction (qPCR) was used to examine miRNA and messenger RNA (mRNA) in NSCLC tissues and cell lines. The roles of miR-221-3p in NSCLC progression and drug resistance were assessed by Western blot analysis, colony formation assay, and CCK-8. Dual-luciferase reporter assay was conducted to evaluate the interaction between miR-221-3p and MDM2. Xenograft tumor models were established by subcutaneously injecting PTX-resistant A549 cells (A549/Taxol) to assess the effect of miR-221-3p on tumor growth. Data regarding miRNAs and target proteins from 20 NSCLC tissues and paired non-cancerous matched tissues were also obtained for correlation analysis.

Results: PTX increased miR-221-3p expression, which regulated MDM2/P53 expression in the PTXsensitive NSCLC strain (A549). Meanwhile, miR-221-3p was rarely expressed and not interfered by PTX in A549/Taxol. Dual luciferase reporter assay confirmed that miR-221-3p specifically binds to MDM2 mRNA. MiR-221-3p down-regulation reduced the sensitivity of A549 cells to PTX, whereas its up-regulation partially reversed the A549/Taxol cells resistance to PTX and increased the chemosensitivity of A549/Taxol cells to PTX in xenograft models. QPCR analysis revealed that miR-221-3p expression increased, whereas the MDM2 level decreased in NSCLC tumor tissues. Furthermore, the result of Western bolt analysis showed that P53 was lowly expressed in tumor tissues with MDM2 overexpression.

Conclusions: MiR-221-3p overexpression could regulate MDM2/p53 signaling pathway to reverse the PTX resistance of NSCLC and induce apoptosis in vitro and vivo.

\section{Introduction}

Lung cancer (LC) is one of the most common causes of cancer-related death worldwide[1-3], and ranked second and first among the new cancer cases and cancer-related mortality in 2018, respectively[4,5]. Non-small cell LC (NSCLC) accounts for $80 \%$ of all LC cases, with a 5-year survival rate of approximately $10-15 \%[6,7]$. For patients with advanced NSCLC who do not receive a molecular targeted therapy or immune checkpoint therapy, the standard first-line treatment remains cytotoxic chemotherapy[8]. Paclitaxel (PTX) is an important first-line treatment of advanced NSCLC[9], and interferes with cell division by promoting microtubule polymerization and promotes apoptosis[10]. However, other anti-tumor mechanisms for PTX remain undiscovered. One shortcoming of PTX is the emergence of drug resistance[11], but the underlying molecular mechanism of PTX resistance is still under investigation.

MicroRNAs (miRNAs) are a class of non-coding RNAs (ncRNAs) that are 18-25 nucleotides long and typically cause messenger RNA (mRNA) degradation or translation inhibition by directly binding to the $3^{\prime}$ 
untranslated region (3' UTR) of their target mRNA[12]. MiRNA is involved in various of cellular processes, including cell survival, proliferation, differentiation, apoptosis, and autophagy, through negative regulation of its targets[13]. The mechanism of miR-221-3p in tumor progression is complex. In 2012, miR-221 was reported to be an oncogene or tumor suppressor depending on the tumor system[14]. MiR221 overexpression in the cancer stroma is associated with malignant potential in colorectal cancer[15]. Oral squamous cell carcinoma cells enhance resistance to doxorubicin by up-regulating miR-221[16]. However, miR-221 can inhibit the growth of erythroleukemia cells via kit receptor down-modulation[17].

In this study, we investigated the aberrant expression of miR-221-3p in NSCLC and elucidated the molecular mechanisms underlying its influence on apoptosis and induction of PTX resistance. Our findings provide novel viewpoints for the anti-tumor mechanisms of PTX and the molecular mechanism of PTX resistance in NSCLC.

\section{Methods}

\subsection{Reagents and antibodies}

PTX was purchased from Aladdin. Dulbecco's Modified Eagle Medium (DMEM)/F12 was purchased from Gibco. Fetal bovine serum (FBS) was purchased from Biological Industries. Trypsin, crystal violet, 3-(4,5dimethylthiazol-2-yl)-2,5-diphenyltetrazolium bromide (MTT) kit, Cell Counting Kit-8, and P53 antibody were purchased from Beyotime Biotechnology. Trizol was purchased from Ambion. RevertAid First Strand complementary DNA (cDNA) Synthesis Kit was purchased from Thermo. SYBR Green Polymerase Chain Reaction (PCR) kit was purchased from Bimake. Glyceraldehyde 3-phosphate dehydrogenase (GAPDH) antibody was purchased from Signalway Antibody. Goat anti-mouse IgG horseradish peroxidase (HRP)conjugated secondary antibody was purchased from Santa Cruz Biotechnology. MDM2 antibody was purchased from Affinity. Polyvinylidene difluoride (PVDF) membrane was purchased from Immobilon. $0.3 \%$ triton-X was purchased from Vetec. Lipofectamine ${ }^{\circledR} 3000$ transfection reagent was purchased from Invitrogen. MiRNA mimics and inhibitors were synthesized by GenePharma (Shanghai, China). Dualluciferase reporter vector plasmid was purchased by GenePharma (Shanghai, China). Dual-luciferase reporter gene fluorescence detection kit was purchased by Promega.

\subsection{Tissue specimens}

A total of 20 NSCLC tumor and adjacent non-cancerous tissues were collected through surgical resection from patients diagnosed between September 2018 and May 2019 at the Second Affiliated Hospital of Soochow University (Suzhou, Jiangsu, China). With the guidance of a skillful pathologist, we collected normal lung samples with a distance of $\geq 2 \mathrm{~cm}$ from the edge of the LC tissue. All patients did not receive radiotherapy and chemotherapy before surgery. All specimens were collected under the guidance of the HIPAA protocol[18]. The study was approved by the Ethics Committee of Second Affiliated Hospital of Soochow University, and written informed consent was obtained from all the patients. TNM stage classification complied with the NCCN Clinical Practice Guidelines in Oncology: Non-Small Cell Lung Cancer (Version 5.2017) [19]. 


\subsection{Cell lines and cell culture}

Human A549 cell lines were obtained from Soochow University (Suzhou, China). Human A549/Taxol cell lines were purchased from Yaji Biotechnology Co., Ltd, Shanghai, China. A549 cells were cultured in DMEM/F12 medium supplemented with $10 \%$ FBS (which contained $100 \mathrm{U} / \mathrm{mL}$ penicillin and $100 \mathrm{mg} / \mathrm{mL}$ streptomycin). A549/Taxol cells were cultured in DMEM/F12 medium supplemented with $10 \%$ FBS (which contained $5 \mu \mathrm{M}$ PTX, $100 \mathrm{U} / \mathrm{mL}$ penicillin, and $100 \mathrm{mg} / \mathrm{mL}$ streptomycin).

\subsection{RNA extraction and quantitative polymerase chain reaction (qPCR) analysis}

According to the manufacturer's protocol, total RNA was extracted with Trizol reagent. According to OD260/280 readings, the purity and concentration of RNA were determined by NanoDrop ND-1000 spectrophotometer. Total RNA (500 ng) was reverse transcribed into cDNA with a final volume of $20 \mathrm{ul}$. RevertAid First Strand cDNA Synthesis Kit (Thermo) was used under standard conditions with random primers and oligo dT primers. According to OD260/280 readings, the purity and concentration of DNA were determined by NanoDrop ND-1000 spectrophotometer. Then, the SYBR Green PCR Kit was used for qPCR. The reaction was set as follows: $94^{\circ} \mathrm{C}$ for $3 \mathrm{~min}, 30$ cycles at $94^{\circ} \mathrm{C}$ for $30 \mathrm{~s}, 55^{\circ} \mathrm{C}$ for $30 \mathrm{~s}$, and $72^{\circ} \mathrm{C}$ for $30 \mathrm{~s}$. The final extension was performed at $72^{\circ} \mathrm{C}$ for $7 \mathrm{~min}$. The results of qPCR normalized to the expression of GAPDH. The results of $\mathrm{qPCR}$ were analyzed relative to the threshold cycle (Ct) value and converted into multiple values according to the rule of $2^{-\Delta \Delta C T}$. The primers used are shown in Table S1.

\subsection{MTT assay}

The cells were seeded into a 96-well plate (Corning) at a density of $5 \times 10^{3}$ cells/well in 200 ul culture medium. After treatment, the cells were incubated in $20 \mathrm{ul} \mathrm{DMEM} / \mathrm{F} 12$ containing $0.5 \mathrm{mg} / \mathrm{ml}$ MTT at $37^{\circ} \mathrm{C}$ for $4 \mathrm{~h}$. Afterward, the supernatant was removed, and the cells were lysed in $150 \mathrm{ul}$ dimethyl sulfoxide (DMSO) for $10 \mathrm{~min}$ at $37^{\circ} \mathrm{C}$. Optical density (OD) values were detected at $490 \mathrm{~nm}$. The obtained values were presented as folds of the control group.

\subsection{Western blot analysis}

Western blot analysis was performed using standard procedures. Briefly, total protein was extracted and isolated by $10 \%$ sodium dodecyl sulfate-polyacrylamide gel electrophoresis (SDS-PAGE) and transferred to a polyvinylidene fluoride (PVDF) membrane. To block non-specifically bound, the membrane was incubated with $5 \%$ skim milk powder for $1 \mathrm{~h}$ at room temperature. Membranes were then incubated with primary antibody against MDM2 or P53 (1:1000) followed by horseradish peroxidase (HRP) labeled secondary antibody and detected by chemiluminescence. Ananti-GAPDH antibody (1:1000) was used as a protein loading control.

\subsection{Dual-luciferase reporter assay}


MDM2 3' UTR was amplified from cDNA of 293 cells and inserted into pGL-3 (Promega, USA). The 293 cells (GenePharma, Shanghai, China) were cotransfected with the wild-type 3'UTR of MDM2 containing the putative miR-221-3p binding site (Site 1: 2709-2715) and mutant MDM2 3' UTR (MDM2-3' UTR) with either miR-NC or mimic-miR-221-3p via Lipofectamine ${ }^{\circledR} 3000$. After transfection, the cells were cultivated at $37^{\circ} \mathrm{C}, 5 \% \mathrm{CO} 2$ for $4 \mathrm{~h}$ Then, the luciferase activities were confirmed using a dual-luciferase reporter assay system according to the manufacturer's protocol.

\subsection{Transfection}

A549 cells were seeded into 6-well plates, incubated overnight, and transfected with inhibitor-miR-221-3p or inhibitor-miR-NC. A549/Taxol cells were transfected with the mimic-miR-221-3p or miR-NC under the same conditions. The sequences used for transfection were listed in Table S2. Lipofectamine ${ }^{\circledR} 3000$ was used as a transfection reagent according to the manufacturer's recommendations. After $48 \mathrm{~h}$ of incubation, cells were used for functional analysis.

\subsection{Colony formation assay}

Transfected A549 or A549/Taxol cells were seeded in 6-well plates at $5 \times 10^{3}$ cells per well. After incubation for $36 \mathrm{~h}$ at $37^{\circ} \mathrm{C}$ in a $5 \% \mathrm{CO}_{2}$ humidified incubator, the cells were incubated with medium supplemented with PTX $(2 \mu \mathrm{M})$ and cultured at $37^{\circ} \mathrm{C}$ in a $5 \% \mathrm{CO}_{2}$ humidified incubator for 7 days. After colony formation was observed, the medium was removed. The cells were washed twice with phosphate buffered saline (PBS), fixed with $4 \%$ formaldehyde for $10 \mathrm{~min}$, and stained with $5 \%$ crystal violet for $10 \mathrm{~min}$. The stained cell area ratio was calculated by randomly photographing 15 fields per well under a $10 \times$ microscope. Finally, after dissolving crystal violet with $10 \%$ glacial acetic acid, optical density (OD) values were detected at $595 \mathrm{~nm}$. The obtained values were presented as folds of the control group.

\subsection{CCK8 assay}

After $48 \mathrm{~h}$ of transfection in 96-well plates, the freshly prepared medium contained PTX at a final concentration of $10 \mu \mathrm{M}$. The medium was added to the wells with 7 replicate wells per set. After $48 \mathrm{~h}$ of incubation, cell viability was measured using CCK-8 kit according to the manufacturer's instructions. The absorbance at $450 \mathrm{~nm}$ was measured using NanoDrop ND-1000 spectrophotometer.

\subsection{Xenograft assay}

All experimental protocols were approved by the Animal Ethics Committee of Soochow University. Animal experiments were carried out following the ARRIVE guidelines[17] and the EU Directive 2010/63/EU for animal experiments[18]. A total of 15 male BALB/c nude mice (4 weeks old) weighing $20.35 \pm 1.0 \mathrm{~g}$ were fed a pellet diet and housed under controlled environment with a temperature of $24 \pm 2^{\circ} \mathrm{C}$ and air humidity of $60 \pm 2 \%$. For the drug-resistant xenograft model, A549/Taxol cells were subcutaneously injected into the armpits of nude mice $\left(1 \times 10^{6}\right.$ cells per animal). From the 10th day after cell injection, the engraftment of tumor was confirmed and the baseline tumor size was evaluated. The xenograft-bearing mouse 
models were randomized into 3 groups, 1) mice were intraperitoneally injected with PTX (15 ug per gram each time, bid) and intratumorally injected with agomir-221-3p (2 OD each time, qd); 2) mice were intraperitoneally injected with PTX and intratumorally injected with PBS; 3 ) mice were intratumorally and intraperitoneally injected with PBS. Tumor formation was monitored by measuring the length $(L)$ and width $(W)$ with calipers every 2 days, and the volumes were calculated using the following formula: ( $L \times$ $\mathrm{W} \times \mathrm{W}) / 2$. All mice were sacrificed 10 days after first PTX injection, and the tumors were neatly excised. Tumor tissues were then subjected to total RNA isolation for qPCR analysis.

\subsection{Statistical analysis}

All statistical analyses were performed using SPSS 22.0 software (IBM) and Graph pad Prism 5.0. Differences between NSCLC tumor and adjacent non-cancerous tissues were analyzed using the Chisquare test. The correlations between miR-221-3p expression levels and clinicopathological factors were further analyzed by one-way ANOVA. The correlations between miR-221-3p expression, and MDM2 expression were explored by Pearson correlation analysis. $\mathrm{P}<0.05$ was considered statistically significant.

\section{Results}

\subsection{PTX up-regulated miR-221-3p, which directly regulated MDM2 and P53 in PTX-sensitive NSCLC strain (A549), and was lowly expressed in PTX-resistant A549 cells (A549/Taxol) cells}

First, miR-221-3p expression was detected via qPCR after PTX treatment in A549 cells and A549/Taxol cells to explore the relationship between miR-221-3p and PTX resistance. After $10 \mu \mathrm{M}$ PTX administration for $48 \mathrm{~h}, \mathrm{~A} 549$ cells were noticed to have cell shrinkage and cell size reduction, whereas the morphological changes of A549/Taxol cells were not evidently observed (Fig. 1A). MTT assay results showed that PTX inhibited NSCLC cell proliferation in a dose-dependent manner. A549/Taxol cells $\left(\mathrm{IC}_{50}\right.$ value $=55.47 \mu \mathrm{M})$ showed evident PTX resistance compared with $\mathrm{A} 549$ cells $\left(\mathrm{IC}_{50}\right.$ value $\left.=17.18 \mu \mathrm{M}\right)$ (Fig. 1B). After treatment of PTX, the miR-221-3p expression was significantly increased in A549 cells (Fig. 1C, $P=0.036$ ), but was extremely low in A549/Taxol cells at only $1 / 3$ of that in A549 cells (Fig. 1C, $P$ $=0.045)$. No significant change was found in the miR-221-3p expression in A549/Taxol cells after PTX treatment (Fig. 1C, $\mathrm{P}=0.070$ ).

Second, MDM2 and P53 levels were analyzed by Western blot to explore the molecular mechanisms of miR-221-3p, and dual-luciferase reporter assay was conducted to verify the interaction between miR-221$3 p$ and MDM2. As shown in Fig. 1D, TargetScanHuman 7.2 was employed first to predict that MDM2 is the putative target of miR-221-3p. According to Western blot analysis, A549 cells had significantly decreased MDM2 protein expression $(P=0.004$, Figs. $1 E$ and $1 F)$, but was significantly increased $P 53$ protein expression $(P<0.001$, Figs. $1 E$ and $1 G)$ after $P T X$ administration. The MDM2 protein expression in A549/Taxol cells was almost three times higher than that in A549 cells $(P<0.001$, Figs. 1E and 1F), 
whereas the P53 protein expression was low at approximately $1 / 8$ of that in $A 549$ cells $(P<0.001$, Figs. $1 E$ and $1 G$ ). No significant was found in the MDM2 and P53 expression in A549/Taxol cells after PTX treatment. MDM2 was sixfold higher than that in A549 + PTX group $(P<0.001$, Figs. 1E and 1F), whereas P53 was approximately $1 / 25$ of that in A549 + PTX group $(P<0.001$, Figs. $1 E$ and $1 G)$. A luciferase reporter plasmid-containing wild-type or mutant MDM2 was used to observe the effects after transfection (Fig. $1 \mathrm{H}$ ), and the luciferase activity was measured $48 \mathrm{~h}$ after transfection. When miR-221-3p was co-transfected with MDM2-WT, the relative luciferase activity was significantly lower than that in the control group ( $P=0.027$, Fig. $1 \mathrm{I})$ or the miR-NC group $(P=0.026$, Fig. $1 \mathrm{I})$. However, when miR-221-3p was co-transfected with MDM2-MT, no observed significance was found (Fig. 1I). These results indicate that miR-221-3p interacts with MDM2.

\subsection{Knockdown or overexpression of miR-221-3p regulated the expression of MDM2 and P53 in A549 cell line}

First, miR-221-3p expression in A549 cells was down-regulated or up-regulated via the transfection of inhibitor-miR-221-3p or mimic-miR-221-3p, and the expression changes of MDM2 and P53 were analyzed by qPCR and Western blot to further validate the miR-221-3p/MDM2/P53 pathway. As shown in Fig. 2A, inhibitor-miR-221-3p was designed to specifically target the binding sites in miR-221-3p. QPCR results in Fig. 2B showed that inhibitor-miR-221-3p and mimic-miR-221-3p transfections significantly down- and upregulated the expression of miR-221-3p to 1/20 $(P<0.001)$ and 500 times $(P<0.001)$ of that in the negative control group, respectively. Therefore, transfection was successful. As shown in Fig. $2 \mathrm{C}$, the expression of MDM2 in A549 cells was up-regulated to 1.6 times of that in negative control group $(\mathrm{P}<$ 0.001) after inhibitor-miR-221-3p transfection, and mimic-miR-221-3p transfection significantly downregulated the expression of MDM2 to $1 / 3$ of that in negative control group $(P=0.0017)$. As shown in Fig. 2D, inhibitor-miR-221-3p transfection up- and down-regulated MDM2 ( $P=0.008$, Fig. 2E) and P53 protein expression $(P=0.040$, Fig. $2 F)$, respectively, whereas mimic-miR-221-3p transfection down- and up-regulated MDM2 expression ( $P=0.022$, Fig. $2 E$ ) and $P 53$ expressions $(P=0.016$, Fig. $2 F)$, respectively. The above results indicated that miR-221-3p was negatively and positively correlated with MDM2 and $\mathrm{P} 53$, respectively, which was consistent with the results shown in Figs. $1 \mathrm{H}$ and $1 \mathrm{I}$.

\subsection{Knockdown and overexpression of miR-221-3p could reduce PTX sensitivity in A549 cell line and reverse PTX resistance in A549/Taxol cell line, respectively}

To further analyze the association between miR-221-3p/MDM2/P53 pathway and PTX resistance, we down- and up- regulated miR-221-3p in A549 and A549/Taxol cells via the transfection of inhibitor- and mimic-miR-221-3p, respectively. Colony formation and CCK-8 assays were then employed to explore the changes of cell proliferation and cell viability in A549 cells and A549/Taxol cells after transfection. Figure 3A shows the cell proliferation ability of A549 and A549/Taxol cells after the transfection of inhibitor- and mimic-miR-221-3p via crystal violet staining, respectively. The stained cell area ratio was calculated in accordance with 15 random fields per well under the $10 \times$ magnification. As shown in Fig. 3B, inhibitor-miR-221-3p transfection increased the proliferation of A549 cells $(P=0.025)$; however, 
this effect was not evident after PTX treatment $(P=0.191)$. Mimic-miR-221-3p transfection significantly inhibited the proliferation of A549/Taxol cells $(P<0.001)$ and increased the sensitivity of A549/Taxol cells to PTX $(P<0.001)$. After dissolving crystal violet with $10 \%$ glacial acetic acid, optical density values were detected at $595 \mathrm{~nm}$ by using the NanoDrop ND-1000 spectrophotometer. As shown in Fig. 3C, inhibitor-miR-221-3p transfection increased the cellular survival of A549 cells $(P<0.001)$; however, this effect was not evident after PTX treatment $(P=0.518)$. As shown in Fig. 3D, mimic-miR-221-3p transfection significantly inhibited cellular survival of $A 549 /$ Taxol cells $(P=0.017)$ and increased the sensitivity of $A 549 /$ Taxol cells to PTX $(P=0.004)$. The above results were consistent with the results shown in Fig. 3B. The cell viability of A549 and A549/Taxol cells treated with PTX after the transfection of inhibitor- and mimic-miR-221-3p was evaluated by CCK-8 assay (Fig. 3E). As shown in Fig. 3F, the absorbance at $450 \mathrm{~nm}$ of each group indicated that inhibitor- and mimic-miR-221-3p transfections could attenuate $(P<0.001)$ and strengthen $(P<0.001)$ the cell viability inhibition of PTX in A549 and A549/Taxol cell lines, respectively. The above results indicated that inhibitor- and mimic-miR-221-3p transfections could enhance PTX resistance in A549 cell line and reverse PTX resistance in A549/Taxol cell line, respectively.

\subsection{MiR-221-3p overexpression could reverse PTX resistance in vivo}

To determine the important role of miR-221-3p on PTX resistance in LC, we constructed drug-resistant xenograft by subcutaneously injecting A549/Taxol cells. As shown in Fig. 4A, the tumor size in the agomir-221-3p group was significantly smaller than those in the PTX group. The tumor size in the blank group was much larger than those in the PTX group (Fig. 4A). We also detected the miR-221-3p and MDM2 expression levels by qPCR analysis (Figs. 4C and 4D). We observed that the tumor growth was significantly suppressed by intratumorally injecting agomir-221-3p (Fig. 4B), with up-regulation of miR221-3p expression (Fig. 4C) and down-regulation of MDM2 expression (Fig. 4D), which validated the effect of miR-221-3P/MDM2/P53 pathway on PTX resistance in vivo.

\subsection{MiR-221-3p was up-regulated in NSCLC tissues and the low expression of miR-221-3p was correlated with advanced T stage}

To further validate the role of the miR-221-3p/MDM2/P53 pathway in NSCLC, in addition to the above cellular and molecular experiments, we also collected 20 samples of NSCLC tumor and adjacent noncancerous tissues through surgical resection from patients diagnosed between September 2018 and May 2019 .

First, qPCR was used to measure the miR-221-3p and MDM2 expression levels in 20 paired NSCLC and paracancerous tissues (Figs. 5A and 5B). As shown in Fig. 5C, miR-221-3p was markedly up-regulated in NSCLC tissues compared with the control $(P=0.032)$. The expression of MDM2 in NSCLC group was significantly lower than that in paracancerous group $(P=0.003$, Fig. 5D), which suggested a negative relationship between miR-221-3p and MDM2. However, no statistically significant correlation was found in 20 paired NSCLC and paracancerous tissues between miR-221-3p and MDM2 ( $R=-0.198, P=0.221$; Fig. 5E). Oncomine database was employed to verify the expression of MDM2 in NSCLC tissue, and the 
results indicated that the expression of MDM2 could be decreased in various pathological types of NSCLC (Fig. 5F).

Second, the correlation between miR-221-3p/MDM2 expression level and other clinicopathological parameters in patients with NSCLC was also analyzed. The mean value of miR-221-3p/MDM2 in NSCLC tissues was used as the threshold for distinguishing the high group and low groups.

Regarding miR-221-3p, the decreased expression of miR-221-3p was evidently related to advanced $T$ stage $(P=0.005$, Table S3; $P=0.008$, Table $S 4)$. In summary, the expression of miR-221-3p in NSCLC tissues was significantly higher than that in paired non-cancerous matched tissues $(P=0.004$, Table S4).

Regarding MDM2, the increased expression of MDM2 was evidently related to advanced T stage $(\mathrm{P}=$ 0.020 , Table S5). In summary, the level of MDM2 expression in NSCLC tissues was significantly lower than that in paired non-cancerous matched tissues $(P=0.004$, Table $S 6)$.

Third, based on the GPCR results in Fig. 5B, 20 paired NSCLC and paracancerous tissues were divided into 5 groups according to the sequence of MDM2 expression from low to high for Western blot experiments (Fig. 6A). The levels of MDM2 and P53 protein are shown in Figs. 6B and 6C, respectively. As shown in Fig. 6D, MDM2 was markedly up-regulated in NSCLC tissues compared with paracancerous tissues in MDM2 high-expression group $(P=0.046)$. However, no significant difference was found between NSCLC and paracancerous tissues in the 4 relatively low-MDM2 expression groups $(P=0.186,0.131,0.479$, 0.470). As shown in Fig. 6E, P53 was markedly down-regulated in NSCLC tissues compared that in paracancerous tissues in two high-MDM2 expression groups $(P=0.013,0.026$ respectively). However, no significant difference was found between NSCLC and paracancerous tissues in the 3 relatively low-MDM2 expression groups $(P=0.201,0.253,0.514)$. A negative relationship between MDM2 and P53 was found in high-MDM2 expression group $(R=-0.748, P=0.033$; Fig. $6 F)$. No statistically significant correlation was found in another 4 relatively low-MDM2 expression groups between MDM2 and P53 ( $P=0.474,0.790$, $0.741,0.409)$. The above results indicated that MDM2 could be associated with the progression of NSCLC in the high-MDM2 expression group, which was negatively correlated with P53.

\section{Discussion}

This study focused to investigate the aberrant expression of miR-221-3p in NSCLC and to elucidate its molecular mechanisms that influence apoptosis and induce PTX resistance. Our results indicate that PTX can regulate the expression of MDM2 and P53 via up-regulating the expression of miR-221-3p in A549 cells. Furthermore, miR-221-3p overexpression could reverse PTX resistance and induce apoptosis via targeting the MDM2/P53 signaling pathway in NSCLC cells. The miR-221-3p up-regulation could increase the chemosensitivity of A549/Taxol to PTX in xenograft models. Based on analysis of NSCLC tissues and paired non-cancer matching tissues, it was found that miR-221-3p was up-regulated in NSCLC tissues, and the low expression of miR-221-3p is associated with poor T staging. This topic provides a new direction for studying the role of microRNA in the development of NSCLC and a new perspective for the analysis of PTX resistance of NSCLC. In addition, miRNA mimics was explored as a new method to reverse PTX resistance. 
PTX can promote the apoptosis of A549 cells by up-regulating the level of long-chain ncRNA MEG3[20]. However, the ncRNA as a mechanism of paclitaxel drugs has been rarely reported. Association studies between PTX and ncRNA have often focused on PTX resistance. In terms of miRNAs, ursolic acid has recently been reported to reverse the chemical resistance of PTX to breast cancer cells by targeting miR149-5p[21]. MiR-155-3p can also act as a tumor suppressor and reverse PTX resistance via the negative regulation of MYD88 in human breast cancer[22]. In 2015, PTX has been reported to cause the miRNA release, including miR-221-3p[23]. In our research, the expression of miR-221-3p was up-regulated by PTX in A549 cells; this founding could be a new mechanism of PTX. Regarding PTX resistence, our results indicated that the low expression of miR-221-3p was associated with NSCLC PTX resistance. To explore methods to reverse PTX resistance to NSCLC cells, we transfected inhibitor- and mimic-miR-221-3p. The results showed that the knockdown of miR-221-3p could reduce PTX sensitivity in A549 cell line whereas the overexpression of miR-221-3p could reverse PTX resistance in A549/Taxol cell line.

In our research, despite the cellular and molecular experiments, 20 of NSCLC tissue and paired noncancerous matched tissue samples were also collected through surgical resection. The level of miR-221$3 p$ increased significantly in NSCLC tissues compared with that in paired non-cancerous matched tissues, which suggested that miR-221-3p could be used as a potential biomarker for NSCLC. The relationship between miRNA and NSCLC has been extensively studied. The recent report suggested that miR-621 was closely related to the pathological grade and poor prognosis of NSCLC. Furthermore, miR-621 can inhibit the malignant progression of NSCLC by modulating SIX4 expression[24]. MiRNA could also be used as a candidate biomarker for the early diagnosis of NSCLC. MiR-23a and miR-451 can be used as potential biomarkers for the early diagnosis of NSCLC, and their combined detection can be effective in diagnosis[25]. MiR-17 and miR-222 can also be considered as non-invasive biomarkers for detecting early LC development and metastasis in patients with NSCLC[26]. In addition, the role of serum miRNA as a prognostic factor in patients with advanced NSCLC and its association with tissue miRNA expression profiles have been studied[27]. MiR-221 is a carcinogenic risk factor and is highly expressed in NSCLC tissues[27], which was consisted with the results from our clinical samples.

Regarding the relationship between MDM2 protein and NSCLC tissues, MDM2 is highly expressed as a proto-oncogene in cancer tissues. MDM2 is significantly up-regulated in lung adenocarcinoma tissues compared with adjacent tissues[28]. Not only limited to LC, after the inoculation of primary bone tumors, MDM2 expression in the inoculated site has also increased significantly compared with that in the control after prolonged time[29]. However, MDM2 expression is not significantly different between cancer and paracancerous tissues in patients with NSCLC according to Western blot analysis results[30]. In our research, although the increased expression of MDM2 was evidently related to advanced T stage, the level of MDM2 expression in NSCLC tissues was significantly lower than that in paired non-cancerous matched tissues. The Oncomine database analysis indicated the low expression of MDM2 in different pathological subgroups. The above results showed that the expression of MDM2 in NSCLC remains uncertain. In addition, the contingency effect caused by the small sample size was also an interference factor. 
Some limitations in our analysis deserve discussion. First, only 20 NSCLC tumor and adjacent noncancerous tissues were collected in this experiment. Limited sample size weakened the proof of the abnormal expression of miR-221-3p in NSCLC. Second, given the small sample size, many false positives in the chi-square test and the Student t-test were found, as shown in Tables S3-6.

\section{Conclusion}

MiR-221-3p was up-regulated by PTX in NSCLC cells, and the low expression of miR-221-3p may be associated with PTX resistance. MiR-221-3p overexpression could regulate MDM2/P53 signaling pathway to reverse PTX resistance of NSCLC and induce apoptosis in vitro and vivo.

\section{Declarations}

\section{Ethics approval and consent to participate}

Animal experiment protocols were approved by the Animal Ethics Committee of Soochow University. This study was also approved by the Ethics Committee of Second Affiliated Hospital of Soochow University, and written informed consent was obtained from all the patients.

\section{Consent for publication}

Not applicable

\section{Data availability}

The datasets used and/or analyzed during the current study are available from the corresponding author on reasonable request.

\section{Conflict of interest}

The authors declare that they have no competing interests.

\section{Funding}

This work was supported by the National Science Foundation of China (No. 81601098), the Second Affiliated Hospital of Soochow University pre-research Project (SDFEYGJ1609), the Second Affiliated Hospital of Soochow University Clinical Discipline Group Project Funding (XKQ 2015008), the International Team of Gastrointestinal Tumor Project Funding (SZYJTD201804), Import Team of Hepatobiliary and Pancreatic Surgery Project Funding (SZYJTD201803) and the Project of State Key 
Laboratory of Radiation Medicine and Protection (GZK1201820), and 2019 Kunshan Key R\&D Plan (Ecological Agriculture and Social Development)-Social Development Science and Technology Project (KS1941).

\section{Author contributions}

Yusong Zhang: Conceptualization, Funding acquisition, Resources, Validation, Writing - review \& editing.

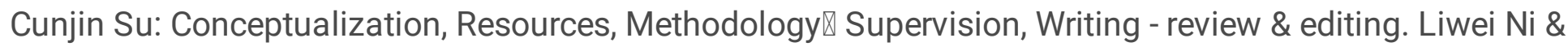
Jianhao Xu \& Fenglun Zhao: Data curation, Formal analysis, Investigation, Methodology, Project administration, Writing - original draft, Writing - review \& editing. Xiaoxiao Dai: Project administration, Resources. Jialong Tao \& Jie Pan \& Aiming Shi \& Zhu Shen: Investigation, Methodology, Project administration, Software.

\section{Acknowledgments}

We acknowledged all organizations that funded our research.

\section{References}

1. Jemal A, Siegel R, Xu J, Ward E. Cancer statistics, 2010, CA Cancer J Clin. 2010;60:5.

2. Siegel R L, Miller K D, Jemal A. Cancer statistics, 2018, CA Cancer J Clin. 2018;68:1.

3. Bray F, Ferlay J, Soerjomataram I, Siegel R L, Torre L A, Jemal A. Global cancer statistics 2018: GLOBOCAN estimates of incidence and mortality worldwide for 36 cancers in 185 countries, CA Cancer J Clin. 2018;68:6.

4. Devesa S S, Bray F, Vizcaino A P, Parkin D M. International lung cancer trends by histologic type: male:female differences diminishing and adenocarcinoma rates rising, Int J Cancer. 2005;117:2.

5. Sanchez de Cos J, Sojo Gonzalez M A, Montero M V, Perez Calvo M C, Vicente M J, Valle M H. Nonsmall cell lung cancer and silent brain metastasis. Survival and prognostic factors, Lung Cancer. 2009;63:1.

6. Fellner S, Bauer B, Miller D S, Schaffrik M, Fankhanel M, Spruss T et al. Transport of paclitaxel (Taxol) across the blood-brain barrier in vitro and in vivo, J Clin Invest. 2002;110:9.

7. Klimaszewska-Wisniewska A, Halas-Wisniewska M, Grzanka A, Grzanka D. Evaluation of AntiMetastatic Potential of the Combination of Fisetin with Paclitaxel on A549 Non-Small Cell Lung Cancer Cells, Int J Mol Sci. 2018;19:3.

8. Hanna N, Johnson D, Temin S, Baker S, Jr., Brahmer J, Ellis P M et al. Systemic Therapy for Stage IV Non-Small-Cell Lung Cancer: American Society of Clinical Oncology Clinical Practice Guideline Update, J Clin Oncol. 2017;35:30. 
9. Razi S S, Rehmani S, Li X, Park K, Schwartz G S, Latif M J et al. Antitumor activity of paclitaxel is significantly enhanced by a novel proapoptotic agent in non-small cell lung cancer, J Surg Res. 2015;194:2.

10. Teow H M, Zhou Z, Najlah M, Yusof S R, Abbott N J, D'Emanuele A. Delivery of paclitaxel across cellular barriers using a dendrimer-based nanocarrier, Int J Pharm. 2013;441:1-2.

11. Reshma P L, Unnikrishnan B S, Preethi G U, Syama H P, Archana M G, Remya K et al. Overcoming drug-resistance in lung cancer cells by paclitaxel loaded galactoxyloglucan nanoparticles, Int J Biol Macromol. 2019;136.

12. Esquela-Kerscher A, Slack F J. Oncomirs - microRNAs with a role in cancer, Nat Rev Cancer. 2006;6:4.

13. Yates L A, Norbury C J, Gilbert R J. The long and short of microRNA, Cell. 2013;153:3.

14. Garofalo M, Quintavalle C, Romano G, Croce C M, Condorelli G. miR221/222 in cancer: their role in tumor progression and response to therapy, Curr Mol Med. 2012;12:1.

15. lida M, Hazama S, Tsunedomi R, Tanaka H, Takenouchi H, Kanekiyo $S$ et al. Overexpression of miR221 and miR222 in the cancer stroma is associated with malignant potential in colorectal cancer, Oncol Rep. 2018;40:3.

16. Du L, Ma S, Wen X, Chai J, Zhou D. Oral squamous cell carcinoma cells are resistant to doxorubicin through upregulation of miR221, Mol Med Rep. 2017;16:3.

17. Felli N, Fontana L, Pelosi E, Botta R, Bonci D, Facchiano F et al. MicroRNAs 221 and 222 inhibit normal erythropoiesis and erythroleukemic cell growth via kit receptor down-modulation, Proc Natl Acad Sci U S A. 2005;102:50.

18. O'Herrin J K, Fost N, Kudsk K A. Health Insurance Portability Accountability Act (HIPAA) regulations: effect on medical record research, Ann Surg. 2004;239:6.

19. Ettinger D S, Wood D E, Aisner D L, Akerley W, Bauman J, Chirieac L R et al. Non-Small Cell Lung Cancer, Version 5.2017, NCCN Clinical Practice Guidelines in Oncology, J Natl Compr Canc Netw. 2017;15:4.

20. Xu J, Su C, Zhao F, Tao J, Hu D, Shi A et al. Paclitaxel promotes lung cancer cell apoptosis via MEG3P53 pathway activation, Biochem Biophys Res Commun. 2018;504:1.

21. Xiang F, Fan Y, Ni Z, Liu Q, Zhu Z, Chen Z et al. Ursolic Acid Reverses the Chemoresistance of Breast Cancer Cells to Paclitaxel by Targeting MiRNA-149-5p/MyD88, Front Oncol. 2019;9.

22. Zhang L, Chen T, Yan L, Xu H, Wang Y, Li Y et al. MiR-155-3p acts as a tumor suppressor and reverses paclitaxel resistance via negative regulation of MYD88 in human breast cancer, Gene. 2019;700.

23. Maushagen R, Pries R, Wollenberg B. [Chemotherapy with paclitaxel leads to microRNA release], Hno. 2015;63:11.

24. Zhang M, Shi H, Zhang C, Zhang S Q. MiRNA-621 inhibits the malignant progression of non-small cell lung cancer via targeting SIX4, Eur Rev Med Pharmacol Sci. 2019;23:11.

25. Cui S, Cao Z, Guo W, Yu H, Huang R, Wu Y et al. [Plasma miRNA-23a and miRNA-451 as candidate biomarkers for early diagnosis of nonsmall cell lung cancer: a case-control study], Nan Fang Yi Ke 
Da Xue Xue Bao. 2019;39:6.

26. Hetta H F, Zahran A M, El-Mahdy R I, Nabil E E, Esmaeel H M, Elkady O A et al. Assessment of Circulating miRNA-17 and miRNA-222 Expression Profiles as Non-Invasive Biomarkers in Egyptian Patients with Non-Small-Cell Lung Cancer, Asian Pac J Cancer Prev. 2019;20:6.

27. Guo J, Meng R, Yin Z, Li P, Zhou R, Zhang S et al. A serum microRNA signature as a prognostic factor for patients with advanced NSCLC and its association with tissue microRNA expression profiles, Mol Med Rep. 2016;13:6.

28. Tang Y, Xuan Y, Qiao G, Ou Z, He Z, Zhu Q et al. MDM2 promotes epithelial-mesenchymal transition through activation of Smad2/3 signaling pathway in lung adenocarcinoma, Onco Targets Ther. 2019;12.

29. Qian G, Hao S, Yang D, Meng Q. P15, MDM2, NF-kappaB, and Bcl-2 expression in primary bone tumor and correlation with tumor formation and metastasis, Int J Clin Exp Pathol. 2015;8:11.

30. Wang B, Liu X, Liu H, Guo J, Zhang T, Zhou N et al. Differential expressions of MDM2 and TAP73 in cancer and cancer-adjacent tissues in patients with non-small-cell lung carcinoma, Pulmonology. 2018.

\section{Figures}



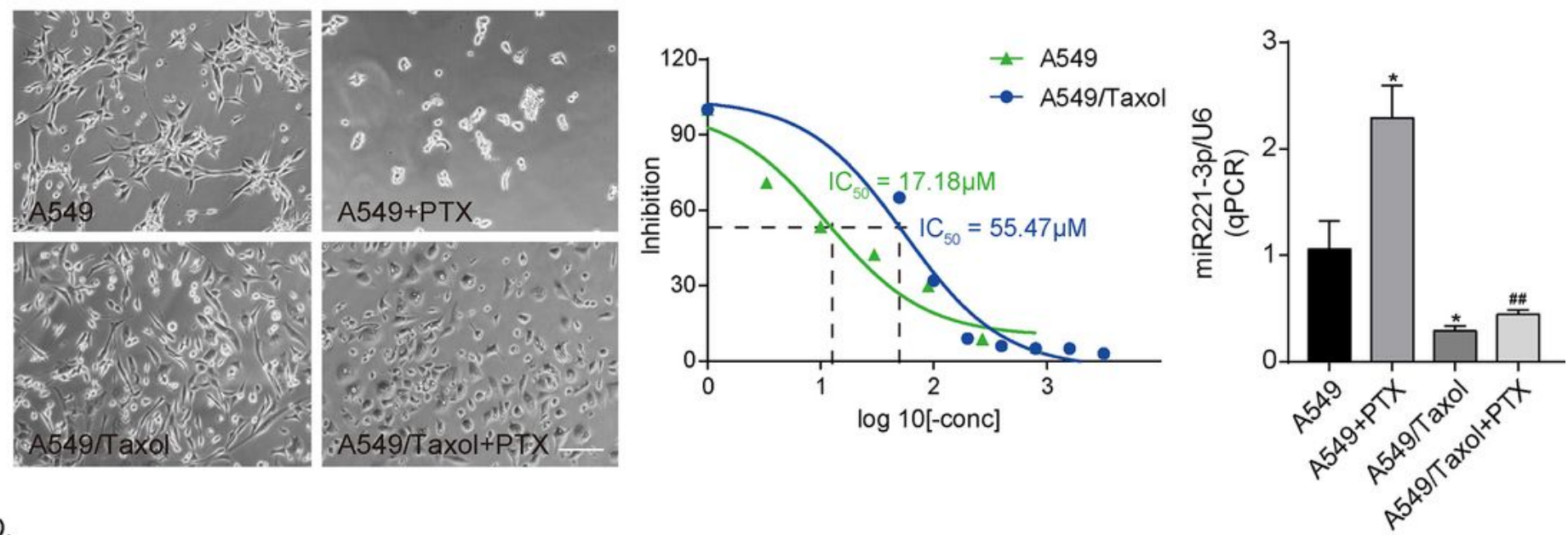

1D.

\begin{tabular}{|c|c|c|c|c|c|c|c|}
\hline & $\begin{array}{l}\text { Predicted consequential pairing of target } \\
\text { region (top) and miRNA (bottom) }\end{array}$ & $\begin{array}{l}\text { Site } \\
\text { type }\end{array}$ & $\begin{array}{l}\text { Context } \\
++ \text { score }\end{array}$ & $\begin{array}{c}\text { Context++ } \\
\text { score } \\
\text { percentile }\end{array}$ & \begin{tabular}{|c|} 
Weighted \\
context++ \\
score
\end{tabular} & \begin{tabular}{|c|}
$\begin{array}{c}\text { Conserved } \\
\text { branch } \\
\text { length }\end{array}$ \\
\end{tabular} & $\mathbf{P}_{\mathrm{CT}}$ \\
\hline $\begin{array}{l}\text { Position 186-192 of MDM2 3' UTR } \\
\text { hsa-miR-221-3p }\end{array}$ & $\begin{array}{l}5^{\prime} \text {...UAAUUUGACUUGAAUAUGUAGCU } \\
\qquad|||||| \mid \\
3^{\prime} \quad \text { CUUUGGGUCGUCUGUUACAUCGA }\end{array}$ & 7 mer-m8 & -0.16 & 82 & -0.16 & 0.614 & $<0.1$ \\
\hline
\end{tabular}

$1 E$.

$1 \mathrm{~F}$.
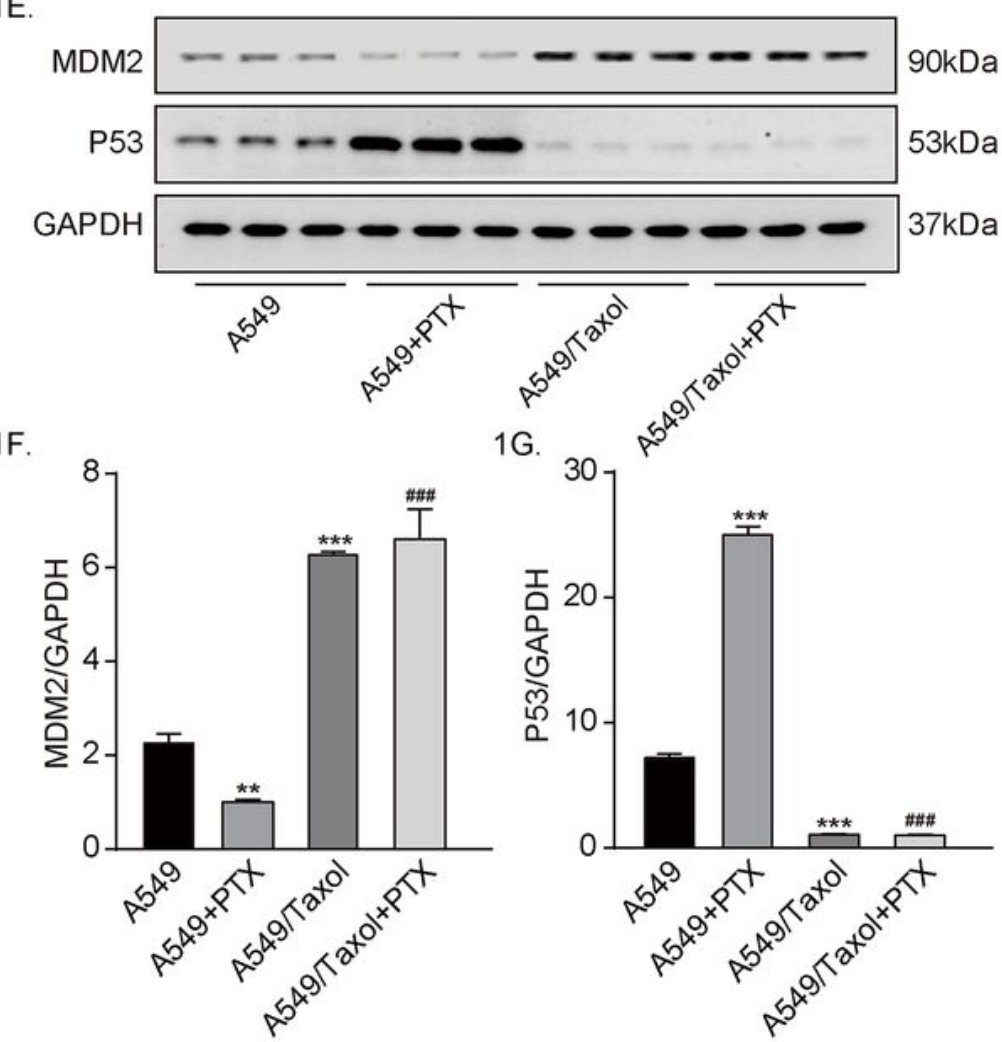

$1 \mathrm{H}$ MDM2 WT

5' ... UAAUUUGACUUGAAUAUGUAGCU.. miR221-3p

3' CUUUGGGUCGUCUGUUACAUCGA MDM2 MT

5' ...UAAUUUGACUUGAAUCGAUUGAU.

11.

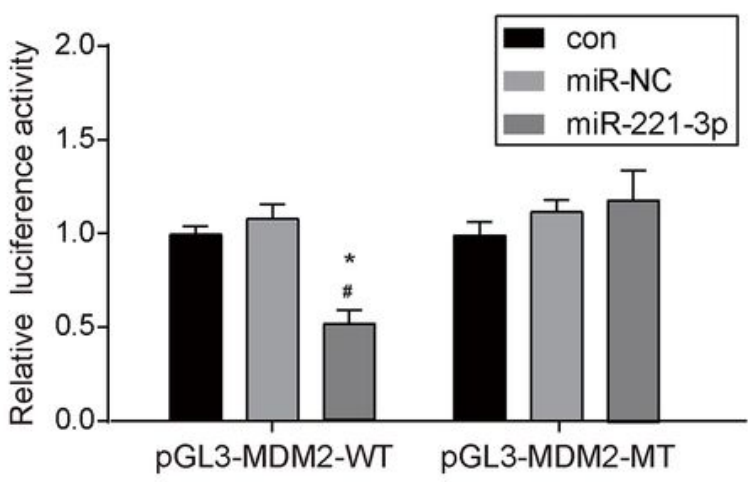

\section{Figure 1}

Differential expression of miR-221-3p and its downstream target MDM2 among NSCLC cell lines. (1A) Cell morphology of A549 and A549/Taxol cells following $10 \mu \mathrm{M}$ PTX administration for $48 \mathrm{~h}$ (images acquired at 10x magnification). (1B) A549 or A549/Taxol cell viability was measured by MTT assay after the treatment of different concentrations of PTX. (1C) miR-221-3p expression was determined by qPCR method after the treatment of PTX in A549 and A549/Taxol cells. (1D) Prediction of the binding stability 
of miR-221-3p and MDM2 mRNA by TargetScan Human 7.2 website. (1E) MDM2 and P53 expression were determined by Western blot after the treatment of PTX in A549 and A549/Taxol cells. (1F) The quantification of MDM2 protein was analyzed according to bands in Fig. 1E. (1G) The quantification of P53 protein was analyzed according to bands in Fig. 1E. (1H) Sequence alignments between miR-221-3p and the seed sequence of MDM2. WT and MT represent wild-type and mutant sequences of MDM2. (11) Results of the dual-luciferase reporter gene assay in 293 cells. $(1 \mathrm{C}, 1 \mathrm{~F}, 1 \mathrm{G}, 1 \mathrm{I})$ Data were presented as means \pm Standard error (SE). (1C, 1F, 1G) ${ }^{\star} p<0.05$, ${ }^{\star *} p<0.01$, ${ }^{\star \star *} p<0.001$, vs A549 group; \#\#p $<0.01$, $\# \#$ \# $<0.001$, vs A549+PTX group. $n=3$ in each group. (1I) * $p<0.05$, vs control group; $\# p<0.05$, vs miR-NC group. $\mathrm{n}=3$ in each group. Scale bar $=100 \mu \mathrm{M}$.

$2 \mathrm{~A}$.

inhibitor-miR-221-3p

5'-CAAACCCAGCAGACAAUGUAGCU-3'

miR-221-3p

3'-CUUUGGGUCGUCUGUUACAUCGA-5'
2D.

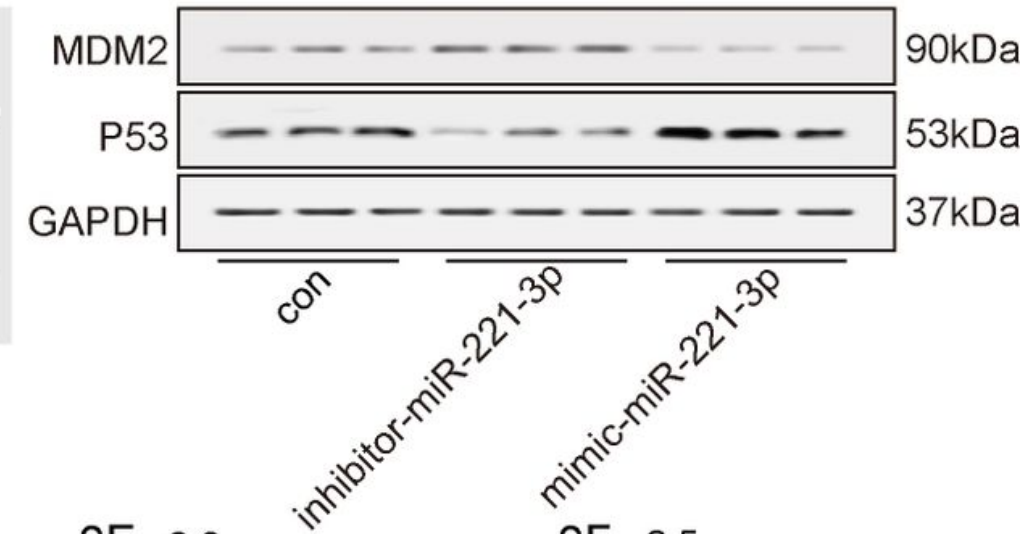

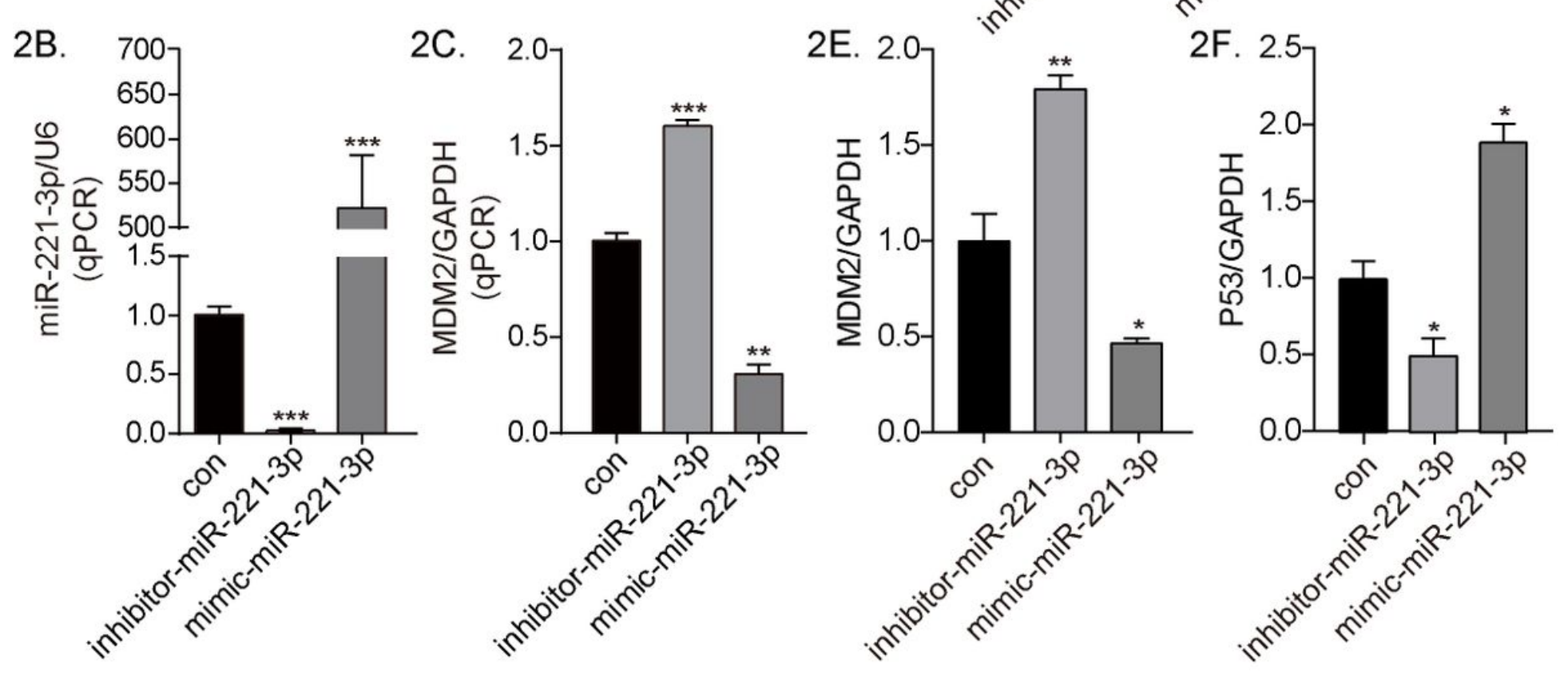

Figure 2

Knockdown or overexpression of miR-221-3p regulated the expression of MDM2 and P53 in A549 cell line. (2A) inhibitor-miR-221-3p specifically targeting the binding sites in miR-221-3p was designed. (2B) miR-221-3p was determined by qPCR method after transfection of inhibitor-miR-221-3p and mimic-miR221-3p. (2C) MDM2 mRNA level was determined by qPCR method after transfection of inhibitor-miR-221$3 p$ and mimic-miR-221-3p. (2D) MDM2 and P53 expression were determined by Western blot after transfection of inhibitor-miR-221-3p and mimic-miR-221-3p. (2E) The quantification of MDM2 protein was 
analyzed according to bands in Fig. 2D. (2F) The quantification of P53 protein was analyzed according to bands in Fig. 2D. (2B, 2D, 2E, 2F) Data were presented as means $\pm S E .{ }^{*} p<0.05,{ }^{\star \star} p<0.01,{ }^{\star \star \star} p<0.001$, vs control group. $n=3$ in each group.

$3 \mathrm{~A}$.
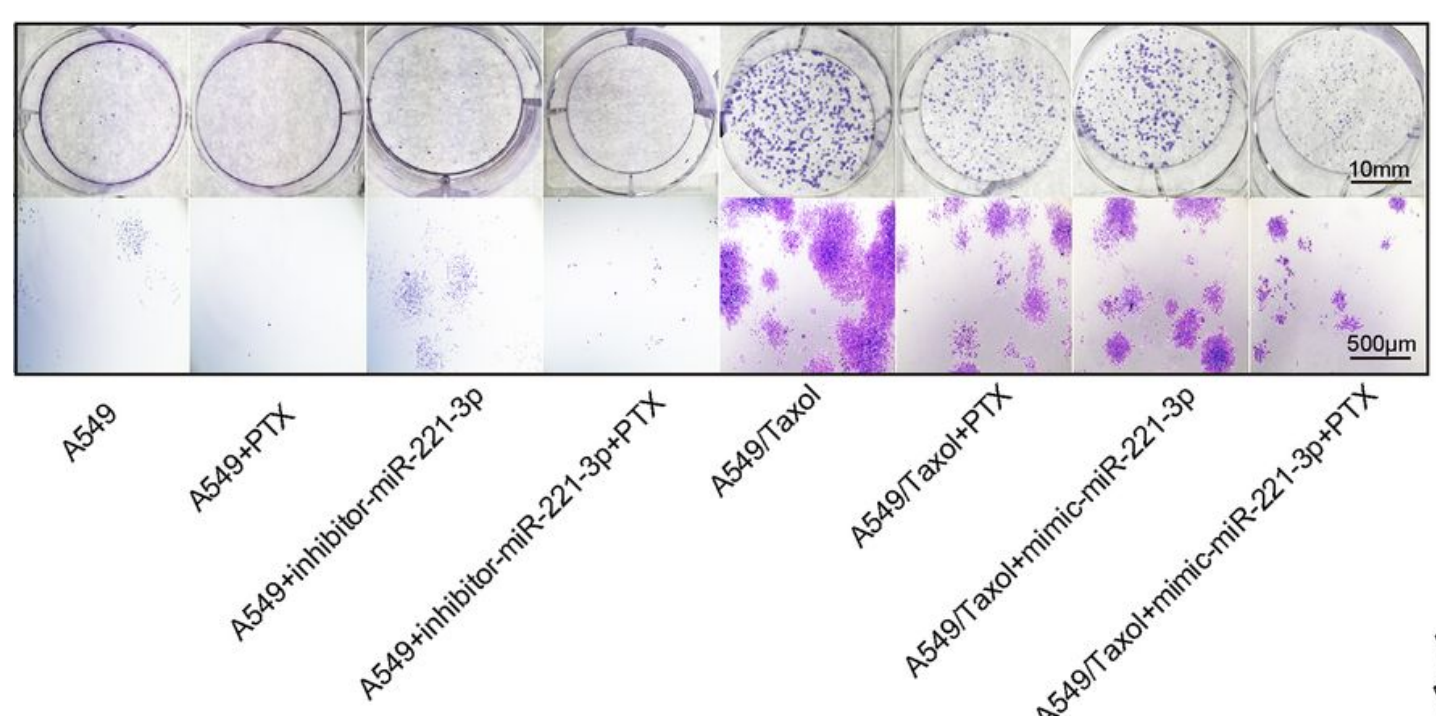

$3 C$.

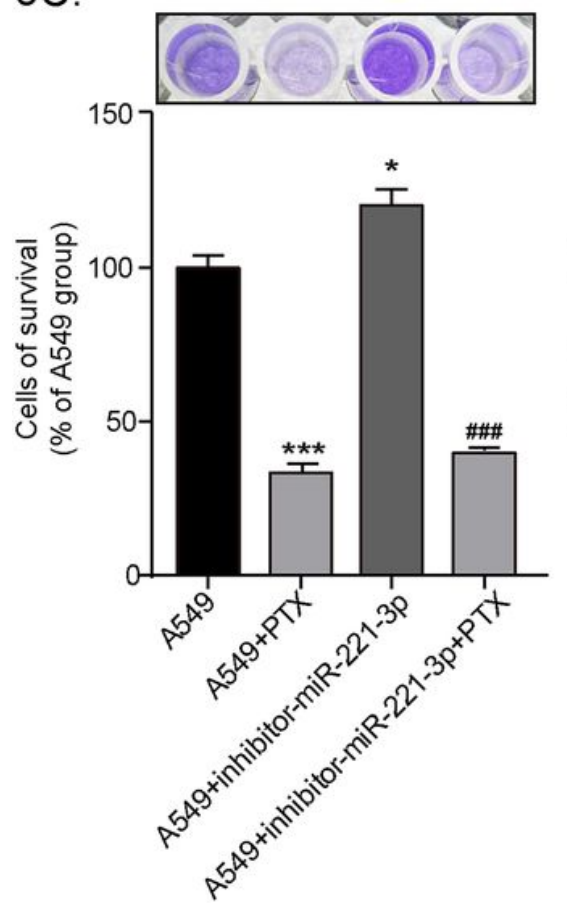

$3 \mathrm{D}$

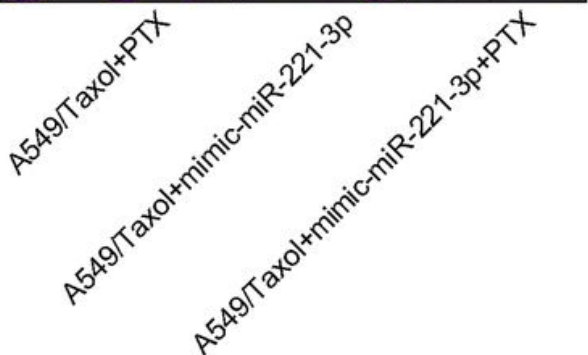

$3 \mathrm{E}$.

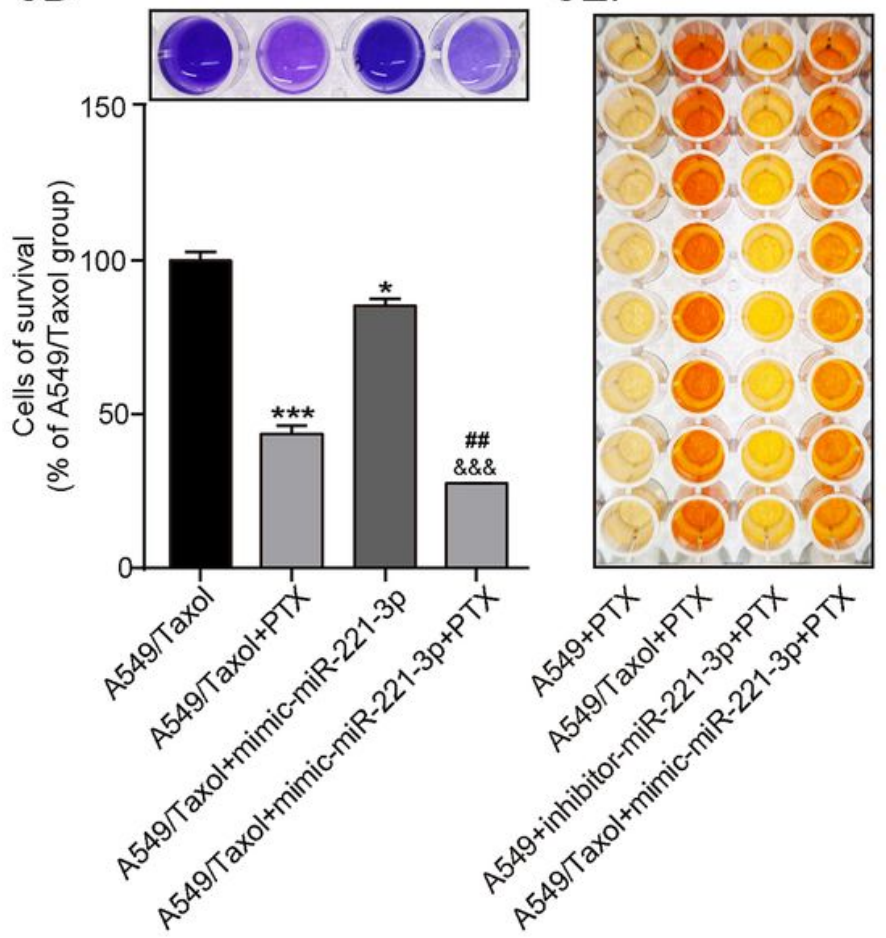

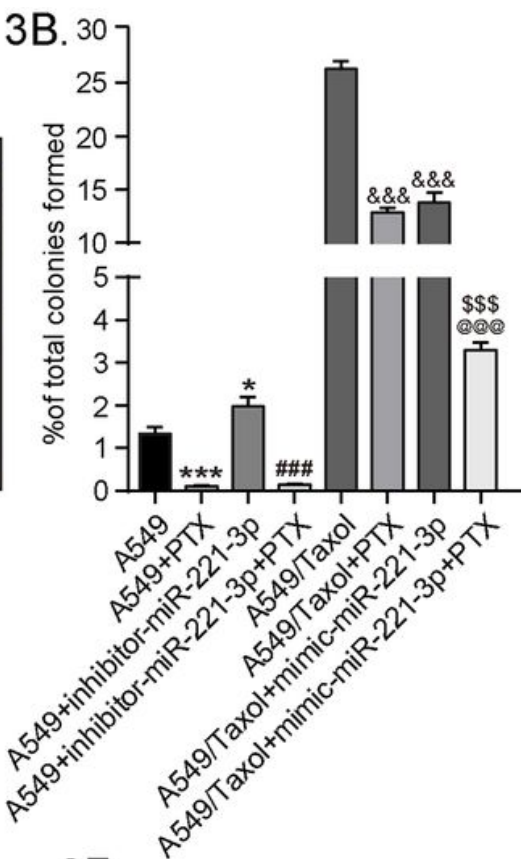

$3 \mathrm{~F}$.

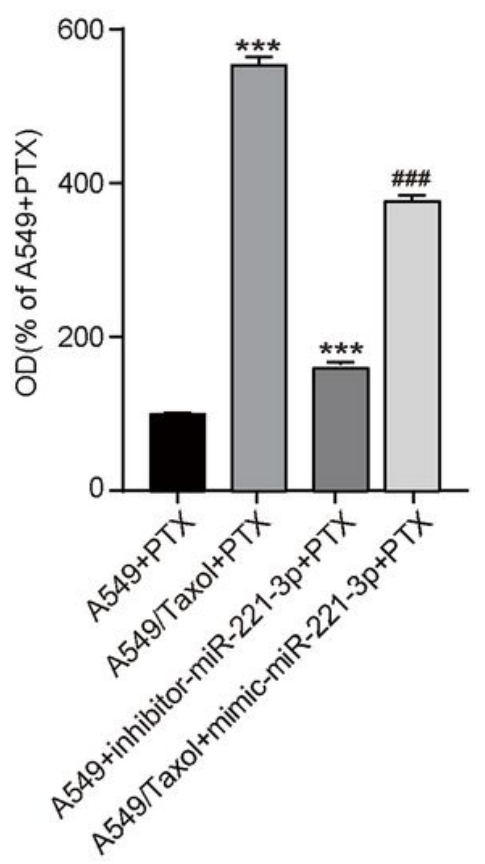

Figure 3

The impact of miR-221-3p expression levels on PTX sensitivity in A549 and A549/Taxol cell lines. (3A) Cell proliferation ability of A549 and A549/Taxol cells treated with PTX after transfection of inhibitor-miR221-3p and mimic-miR-221-3p was evaluated by colony formation assay and crystal violet staining assay. (3B) The stained cell area ratio was calculated according to 15 random fields per well in Fig. $3 \mathrm{~A}$ (images acquired at 10x magnification). (3C) OD values of 4 groups with A549 cells were detected at 
$595 \mathrm{~nm}$ using the NanoDrop ND-1000 spectrophotometer. (3D) OD values of 4 groups with A549/Taxol cells were detected at $595 \mathrm{~nm}$ using the NanoDrop ND-1000 spectrophotometer. (3E) Cell viability of A549 and A549/Taxol cells treated with PTX after transfection of inhibitor-miR-221-3p and mimic-miR-221-3p was evaluated by CCK-8 assay. (3F) The absorbance at $450 \mathrm{~nm}$ of 4 groups in Fig. $3 \mathrm{E}$ was measured using NanoDrop ND-1000 spectrophotometer. (3B, 3C, 3D, 3F) Data were presented as means \pm SE. (3B) ${ }^{*} p<0.05$, *** $p<0.001$, vs A549 group; \#\#\#p <0.001, vs A549+inhibitor-miR-221-3p group; \&\&\&p <0.001, vs A549/Taxol group; \$\$p <0.001, vs A549/Taxol+PTX group; @@@p <0.001, vs A549/Taxol+mimic-miR221-3p group. $n=3$ in each group. (3C) * $<<0.05$, $* \star * p<0.001$, vs $A 549$ group; \#\#\#p <0.001, vs A549+inhibitor-miR-221-3p group. $n=3$ in each group. (3D) ${ }^{*} p<0.05$, $* \star \star p ~<0.001$, vs $A 549 /$ Taxol group; $\# \# p<0.01$, vs A549/Taxol+PTX group; \&\&\&p <0.001, vs A549+mimic-miR-221-3p group. $n=3$ in each group. (3F) ${ }^{\star \star \star} p<0.001$, vs A549+PTX group; \#\#\#p <0.001, vs A549/Taxol+PTX group. $n=3$ in each group. Scale bar=10mm (upper) or $500 \mathrm{Mm}$ (lower).

$4 \mathrm{~A}$.

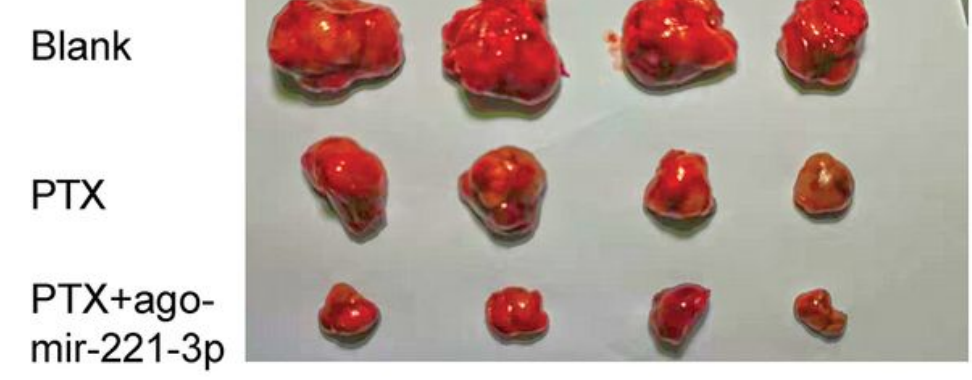

$4 \mathrm{C}$.
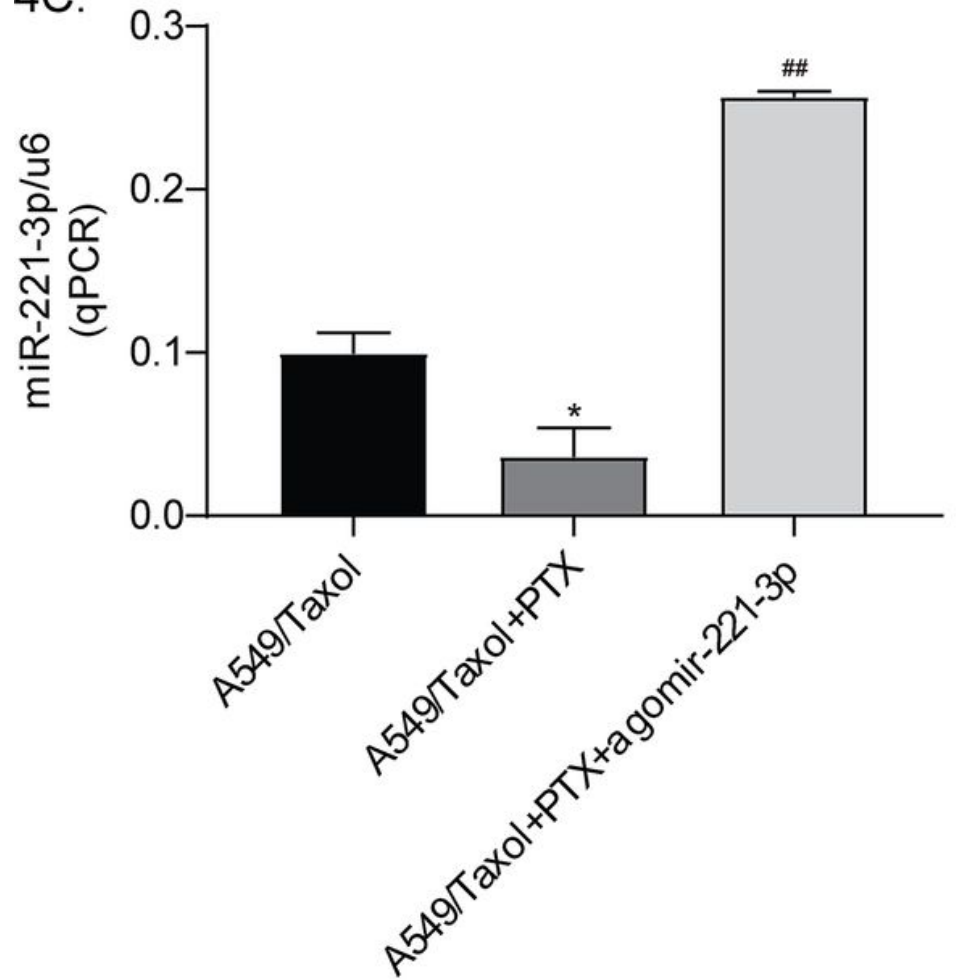

4B.

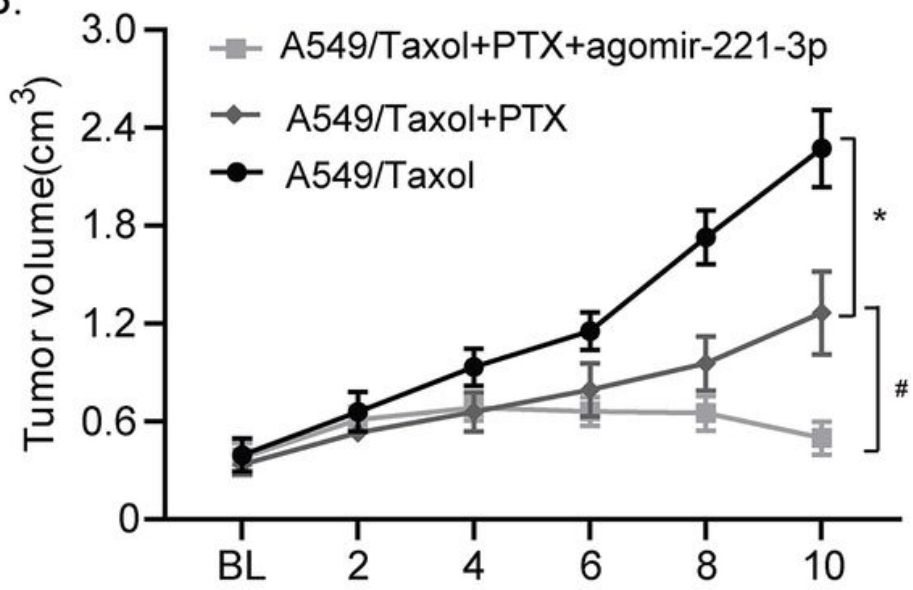

4D.
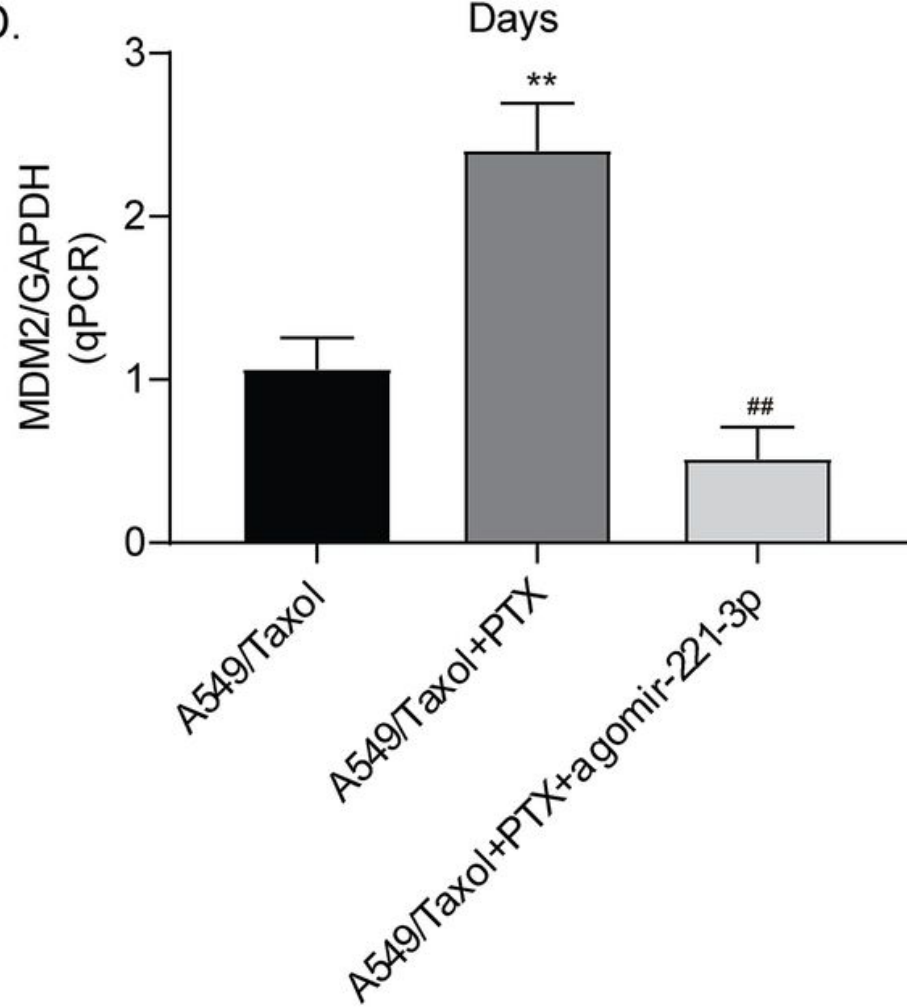

Figure 4 
In vivo effects of miR 221-3p overexpression on tumor growth in drug-resistant xenograft model. (4A) The gross morphology of tumors measured on day 10 after injecting agomir-221-3p plus PTX, or PTX, or PBS (Blank). (4B) Growth curves of subcutaneous xenograft tumors. Tumor volumes were calculated as length $\times$ (square of width)/2. BL, baseline tumor volume. (4C, 4D) qPCR analysis was performed to detect the expression of miR-221-3p and MDM2 in tumor tissues. (4B, 4C, 4D) Data were presented as means \pm SE. (4B) * $p<0.05$, vs A549+PTX group; \#p<0.05, vs A549/PTX+PTX group. $n=5-8$ in each group. (4C, 4D) ${ }^{*} p<0.05,{ }^{* *} p<0.01$, vs A549/PTX group; \#\# $p<0.01$, vs A549/PTX+PTX group. $n=4$ in each group.
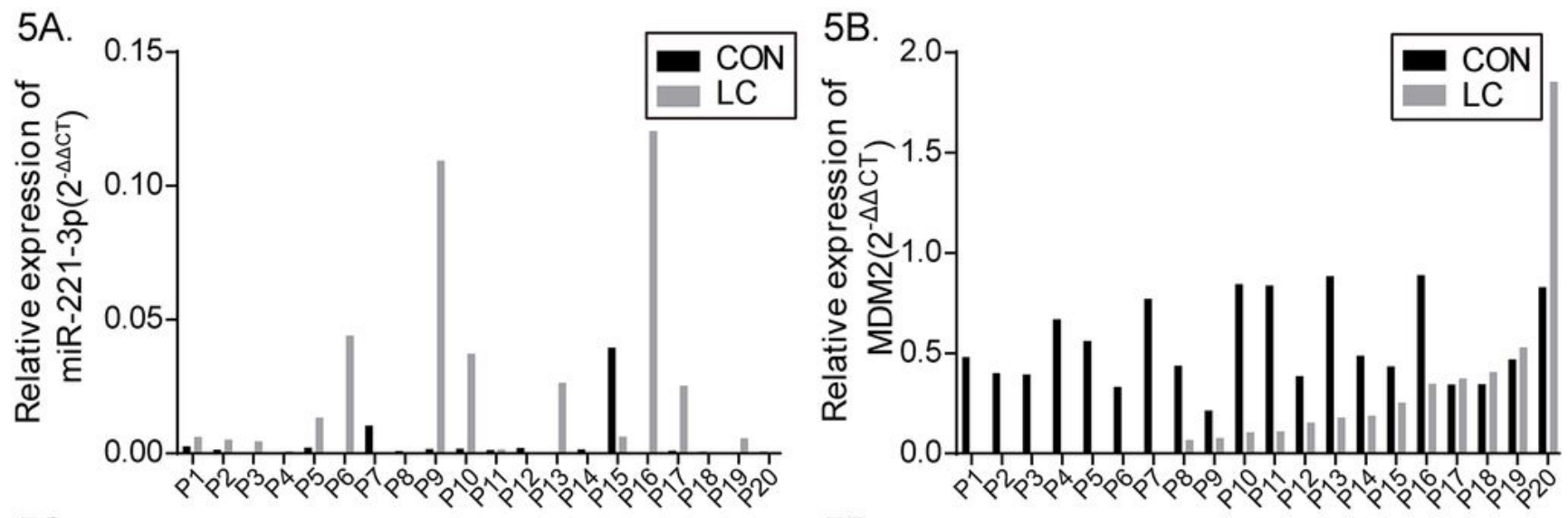

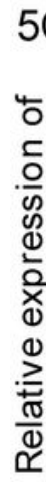
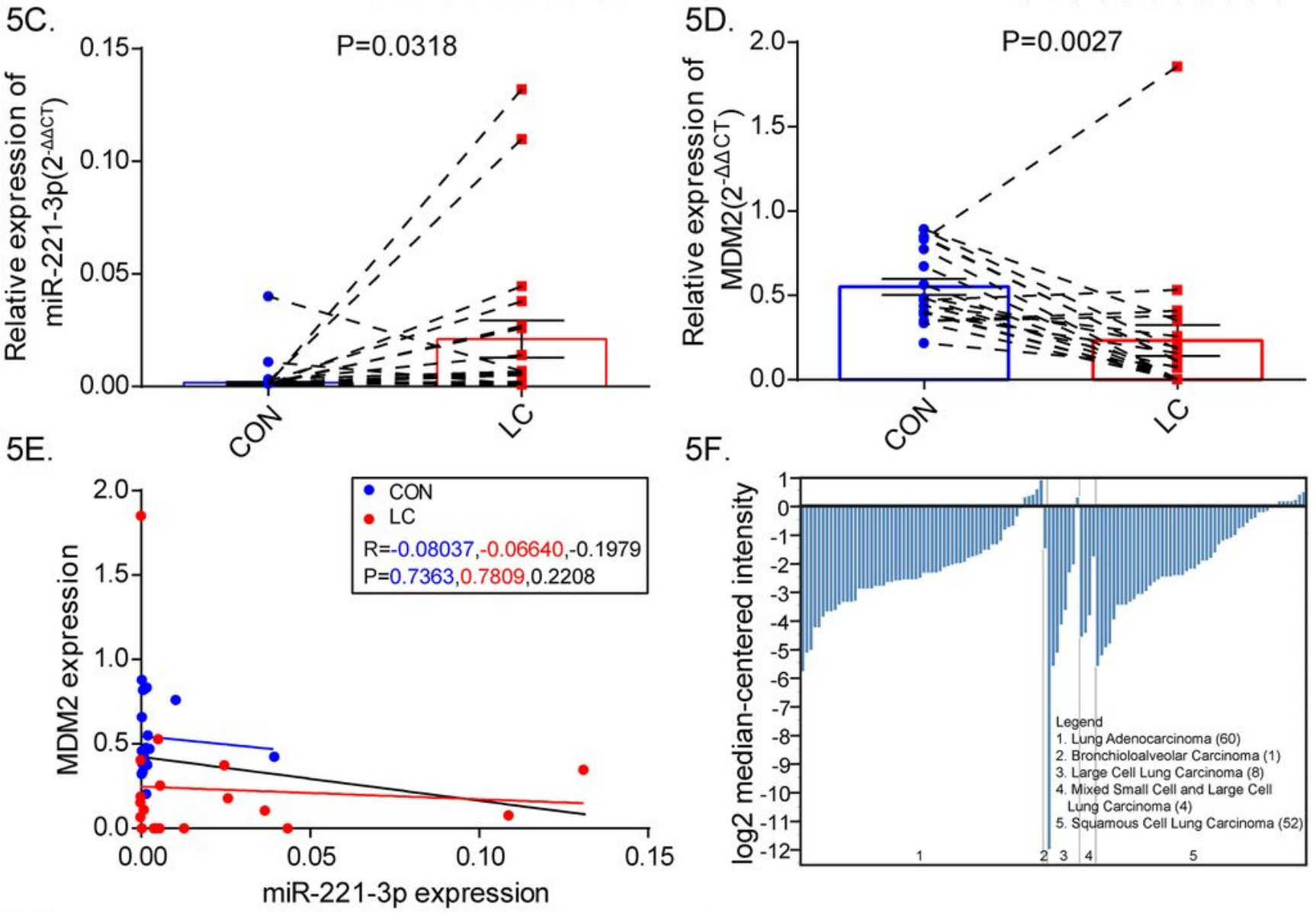

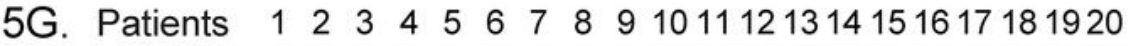
Adjacent Tumor

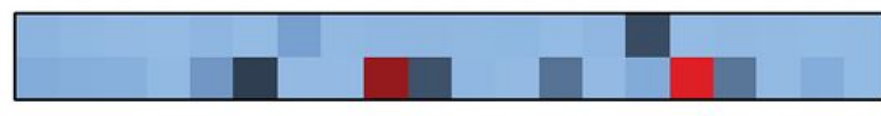

Adjacent Tumor

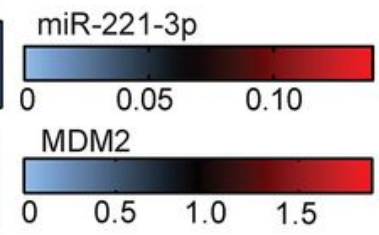




\section{Figure 5}

Expression levels of miR-221-3p and MDM2 in NSCLC tissues and paired non-cancerous tissues. (5A, 4B) Levels of miR-221-3p and MDM2 were measured using qPCR compared with GAPDH/U6 and calculated using the equation 2- $\Delta \Delta C T$. (5C, 4D) Schematic representation of the expression level of miR-221-3p and MDM2 in 20 NSCLC tissues compared with paired non-cancerous matched tissues. (5E) Correlation analysis between miR-221-3p expression and MDM2 expression via Spearman Rank test. (5F) Analysis of MDM2 expression in different pathological types of NSCLC via Oncomine database. (5G) Heat map of the relative expression in 20 patients. $(5 \mathrm{C}, 5 \mathrm{D})$ Data were presented as means $\pm \mathrm{SE}$. 
$6 \mathrm{~A}$.
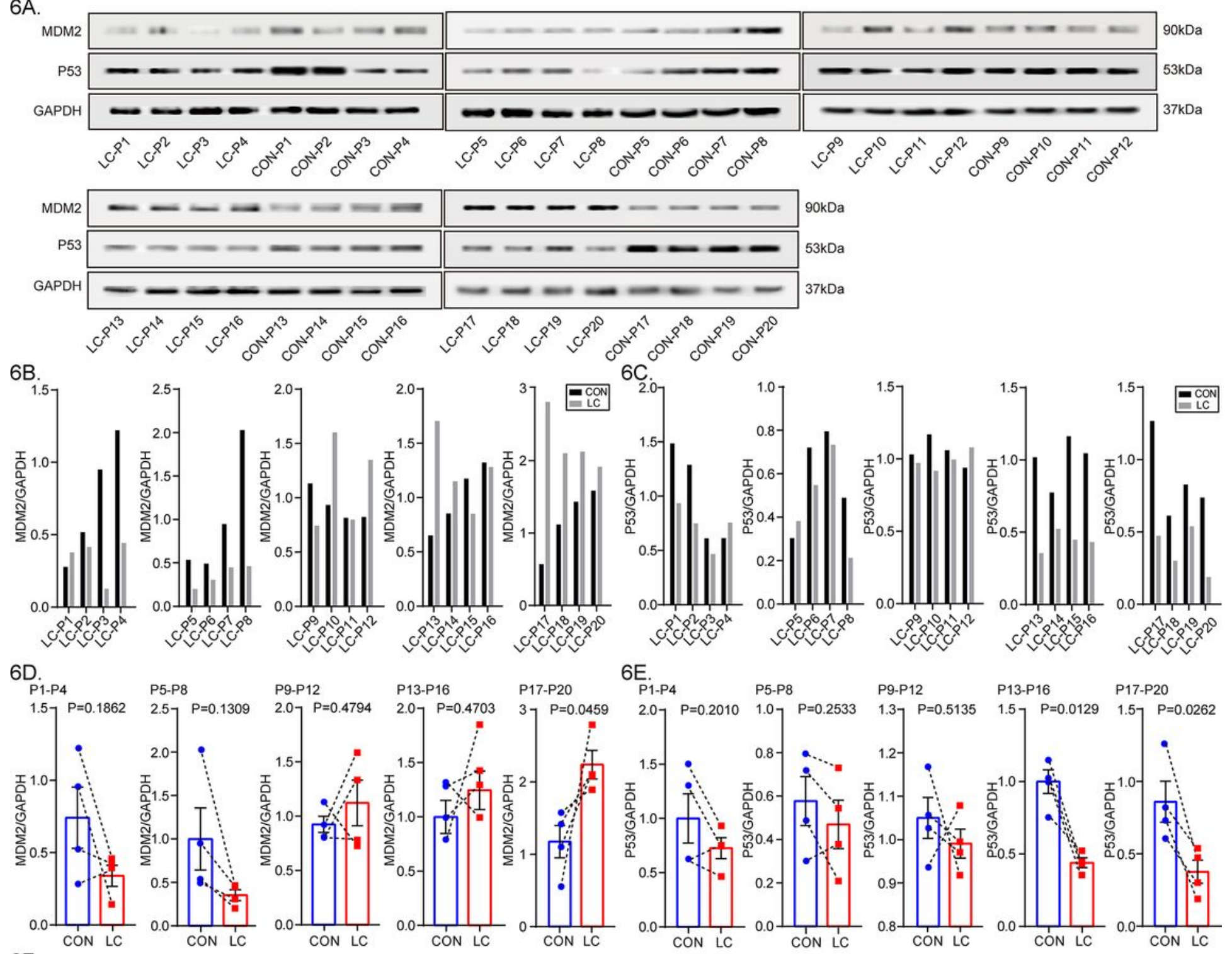

$6 \mathrm{E}$.
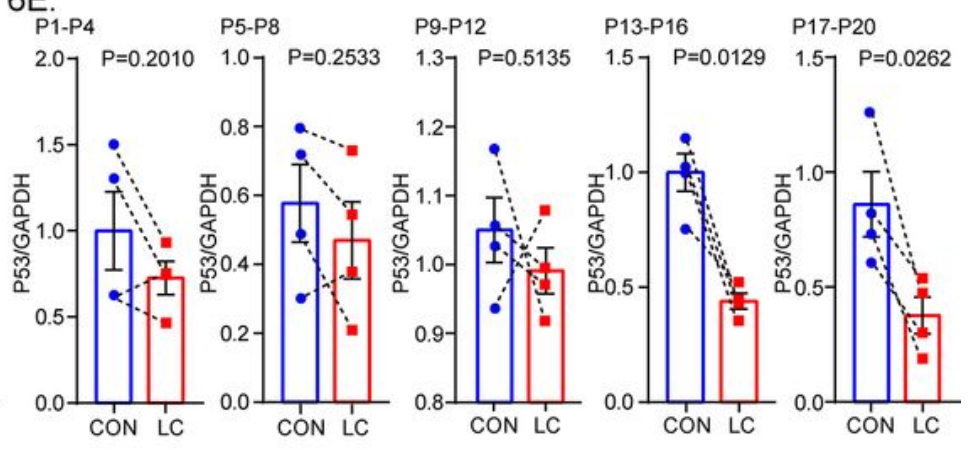

$6 \mathrm{~F}$
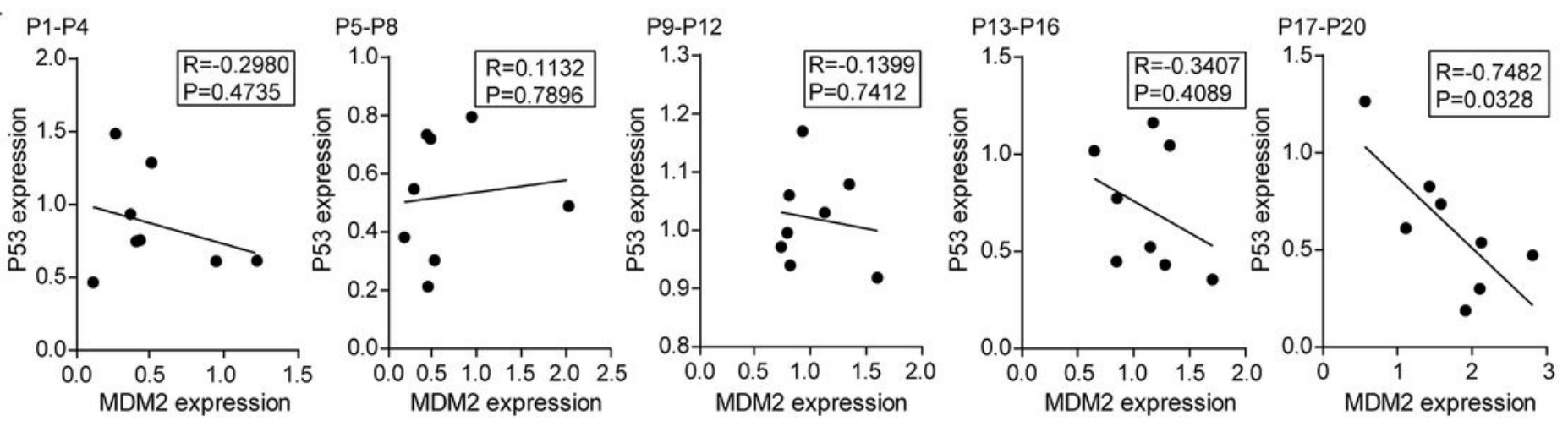

\section{Figure 6}

Expression levels of MDM2 and P53 protein in NSCLC tissues and paired non-cancerous tissues. (6A) MDM2 and P53 expression in 20 NSCLC tissues compared with paired non-cancerous matched tissues were determined by Western blot. (6B) The quantification of MDM2 protein was analyzed according to bands in Fig. 5A. (6C) The quantification of P53 protein was analyzed according to bands in Fig. 6A. (6D, $6 \mathrm{E})$ Schematic representation of the expression level of MDM2 and P53 in 20 NSCLC tissues compared 
with paired non-cancerous matched tissues. (6F) Correlation analysis between MDM2 expression and P53 expression via Spearman Rank test. $(6 \mathrm{D}, 6 \mathrm{E})$ Data were presented as means $\pm \mathrm{SE}$.

\section{Supplementary Files}

This is a list of supplementary files associated with this preprint. Click to download.

- SupplementaryTableS6.docx

- SupplementaryTableS5.docx

- SupplementaryTableS4.docx

- SupplementaryTableS3.docx

- SupplementaryTableS2.docx

- SupplementaryTableS1.docx 